\title{
Chronic complications and quality of life of patients living with sickle cell disease and receiving care in three hospitals in Cameroon: a cross-sectional study
}

Anne M. Andong ${ }^{1,2}$, Eveline D. T. Ngouadjeu ${ }^{3,4}$, Cavin E. Bekolo ${ }^{5}$, Vincent S. Verla ${ }^{1}$, Daniel Nebongo², Yannick Mboue-Djieka ${ }^{2}$ and Simeon-Pierre Choukem ${ }^{1,2,4^{*}}$

\begin{abstract}
Background: Sickle Cell Disease (SCD) is associated with chronic multisystem complications that significantly influence the quality of life (QOL) of patients early in their life. Although sub-Saharan Africa bears $75 \%$ of the global burden of SCD, there is a paucity of data on these complications and their effects on the QOL. We aimed to record these chronic complications, to estimate the $\mathrm{QOL}$, and to identify the corresponding risk factors in patients with SCD receiving care in three hospitals in Cameroon.

Methods: In this cross-sectional study, a questionnaire was used to collect data from consecutive consenting patients. Information recorded included data on the yearly frequency of painful crisis, the types of SCD, and the occurrence of chronic complications. A 36-Item Short Form (SF-36) standard questionnaire that examines the level of physical and mental well-being, was administered to all eligible participants. Data were analyzed with STATA ${ }^{\oplus}$ software.

Results: Of 175 participants included, 93 (53.1\%) were female and 111 (aged $\geq 14$ years) were eligible for QOL assessment. The median (interquartile range, IQR) age at diagnosis was 4.0 (2.0-8.0) years and the median (IQR) number of yearly painful crisis was 3.0 (1.0-7.0). The most frequent chronic complications reported were: nocturnal enuresis, chronic leg ulcers, osteomyelitis and priapism $(30.9 \%, 24.6 \%, 19.4 \%$, and $18.3 \%$ respectively). The prevalence of stroke and avascular necrosis of the hip were $8.0 \%$ and $13.1 \%$ respectively. The median (IQR) physical and mental scores were 47.3 (43.9-58.5) and 41.0 (38.8-44.6) respectively. Age and chronic complications such as stroke and avascular necrosis were independently associated with poor QOL.
\end{abstract}

Conclusions: In this population of patients living with SCD, chronic complications are frequent and their $\mathrm{QOL}$ is consequently poor. Our results highlight the need for national guidelines for SCD control, which should include new-born screening programs and strategies to prevent chronic complications.

Keywords: Sickle cell disease, Chronic complications, Prevalence, Quality of life, Cameroon

\footnotetext{
*Correspondence: schoukem@gmail.com

'Department of Internal Medicine and Pediatrics, Faculty of Health Sciences,

University of Buea, Buea, Cameroon

${ }^{2}$ Health and Human Development (2HD) Research Network, P.O. Box 4856,

Douala, Cameroon

Full list of author information is available at the end of the article
} International License (http://creativecommons.org/licenses/by/4.0/), which permits unrestricted use, distribution, and reproduction in any medium, provided you give appropriate credit to the original author(s) and the source, provide a link to the Creative Commons license, and indicate if changes were made. The Creative Commons Public Domain Dedication waiver (http://creativecommons.org/publicdomain/zero/1.0/) applies to the data made available in this article, unless otherwise stated. 


\section{Background}

Sickle cell disease (SCD) is often associated with chronic complications in the long term [1]. These complications include consequences of chronic anemia and susceptibility to infections owing to functional splenectomy, and may lead to a poor quality of life (QOL) [2]. The World Health Organization (WHO) estimates that 300,000 children are born with SCD each year, 75\% of whom are in sub-Saharan Africa (SSA); they also state that the burden of the disease could be reduced by simple careful management and prevention programs $[3,4]$.

The WHO also recommends that a global management be put in place to reduce SCD morbidity (chronic complications) and mortality, and to improve on the QOL [3]. The disease morbidity and mortality improved in two small samples of patients in Nigeria and Angola using these simple but cost-effective interventions recommended by the WHO [5, 6]. However, data especially those focusing on QOL are still scanty or inexistent in most SSA countries.

To the best of our knowledge, chronic complications that have been reported in Cameroon -a SCD endemic country- are stroke (6.7\%) [7] and gall stone diseases (30\%) [8]. The aim our study was to assess a group of children and adults living with SCD, with particular reference to the types and determinants of the QOL and complications of SCD, in order to inform the actions that could be undertaken to reduce the burden of the disease and to improve the QOL.

\section{Methods}

\section{Study design, setting and participants}

We carried out a cross-sectional study over a period of five months, from November 2014 to March 2015, in three hospitals in Cameroon: the Douala General Hospital, a country reference hospital, the Douala Laquintinie Hospital, which has a sickle cell care center in Douala, and the Buea Regional Hospital, which is the reference hospital for the South-West Region of the country. The first two hospitals are located in the Littoral Region and the third in South-West Region. The two regions are at the coastal area of the country and serve as university teaching hospitals for our Faculty of Health Sciences of The University of Buea. Recruitment of participants was done at the inpatient and outpatient units and during their monthly visits at the Laquintinie Hospital. All the centers had comprehensive medical records. All patients with SCD confirmed by a hemoglobin electrophoresis were consecutively included if they gave their informed written consent or assent to participate. Patients in sickle cell crises at the time of the study were not considered (for QOL assessment), until they completely recovered from the crises as indicated by their caring physician.
All patients above the age of 5 years were included in the assessment of chronic complications because complications such as stroke have been shown to occur as early as the age of 5 years in children with sickle cell disease [9]. Only patients above 14 years were included in the assessment of the QOL, because the short form 36 questionnaire has been validated in sickle cell population at or above this age [10].

\section{Definition of terms and variables}

Sickle cell disease had been diagnosed by haemoglobin electrophoresis. Painful sickle cell crises were defined as any bony painful event in the absence of any recent trauma, for which a medical consultation was done or not. Chronic leg ulcers were defined as any leg wound that had lasted longer than three months. Stroke was defined as any sudden onset neurological dysfunction (mainly one side body weakness) in the absence of trauma, that resolved or not. Avascular necrosis of the hip was self-reported or collected from medical records. Immunization status relating to pneumococcal vaccine, meningococcal vaccine, Typhim Vi (against typhoid fever) and Hepatitis B vaccine) was also recorded.

\section{Data collection and score calculation}

All participants underwent a comprehensive multisystem physical examination. Data on chronic complications were collected by use of a questionnaire (Additional file 1) that contained information on the history obtained from the participant and/or the guardian. Additional clinical data were retrieved from the patient's medical record.

The Short Form (SF)-36 either self-administered or interviewer-administered was used to collect data on the QOL (Additional file 1). This questionnaire reviewed both physical and mental aspect of health comprising eight scored scales each belonging to the two main scores known as Physical and Mental health component scores. The SF 36 form was clearly explained and selfadministered except for participants who did not understand the questions. All the 8 components were assessed through 11 questions. An overall score, physical component score and mental component score were computed. Individual scores for all 8 components were also given. The scores were then standardized using the online newborn screening (NBS) calculator so that the values could be compared to other populations, both the healthy and sickle cell populations. Only one investigator administered the questionnaire to all participants.

\section{Data analysis}

The data set was checked for logical inconsistencies, invalid codes, omissions and improbable data by tabulating, summarizing, describing and plotting variables, depending on their nature. Missing observations were systematically 
excluded. Summary statistics were presented as proportions for categorical variables, as mean and standard deviation for normally distributed continuous variables and as median and interquartile range (IQR) for continuous variables with a skewed distribution. Associations between QOL scores and exposure variables were evaluated by a linear regression model. Variables associated with Total SF-36 score, PCS and MCS in separate univariate analyses at the $5 \%$ significance level were included in respective multivariate linear regression models. Backward elimination based on a p-value lower than 0.05 was used to retain variables that were independently associated with each QOL scores. Adjusted regression and correlation coefficients with their $\mathrm{p}$-values and $95 \%$ confidence intervals $(\mathrm{CI})$ were obtained. The goodness of model fit was assessed by post-estimation of homoscedasticity of residuals.

\section{Results}

In this study 182 participants met the inclusion criteria of which 175 finally took part in the study giving a response rate of $96.2 \%$ (Fig. 1). Of these, 94 (54.9\%) were recruited at Laquintinie Hospital, 72 (41.1\%) at Douala General Hospital and $9(5.1 \%)$ at Buea Regional Hospital.

\section{General characteristics of the participants}

Of the 175 participants, 93 (53.1\%) were females. The median (IQR) age at which the diagnosis of SCD was confirmed was 4.0 years $(2.0-8.5)$; $113(64.6 \%)$ participants were below the age of 21 and therefore needed consent by proxy, 21 being the age of majority in Cameroon. The median (IQR) age was 16.0 years $(9.0-$ 24.0). Concerning ongoing treatment, 122 (69.7\%) patients were on folic acid alone, $1(0.6 \%)$ on a vasodilator only, 17 (9.7\%) on both folic acid and hydroxyurea, 21 (12.0\%) on both folic acid and a vasodilator, $1(0.6 \%)$ were on all three medications and $13(7.4 \%)$ were not taking any medication. Most of the participants 103 (58.9\%) did not have their vaccines up-to-date. Only $75(42.9 \%)$ had regular medical

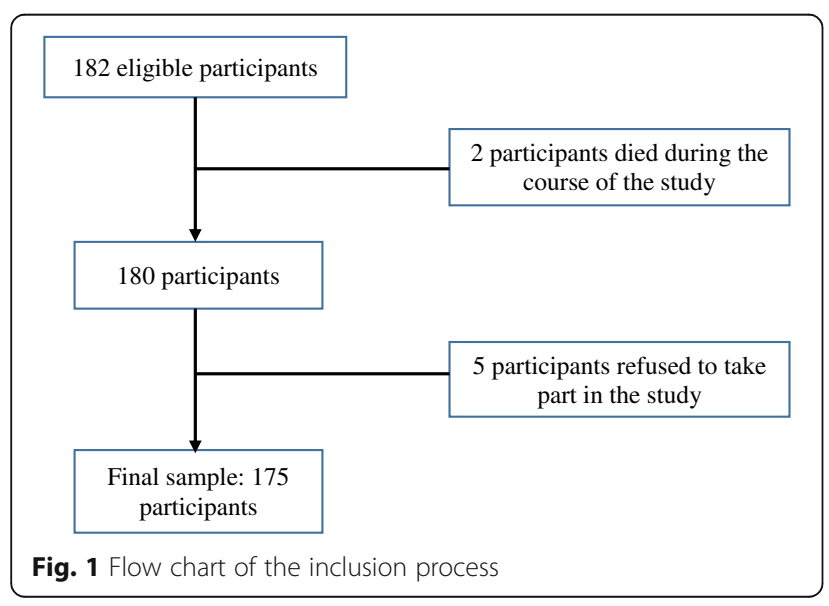

follow-up at the time of the study, 45(25.7\%) being seen by pediatricians. Hemoglobin electrophoresis results were available for 58 (33.1\%) participants and distributed as follow: 28 (48.3\%) SSFA, 16 (27.6\%) SSA 2,10 (17.2\%) SSF, 3 (5.2\%) SS, and 1 (1.7\%) SSC. The median number of yearly painful sickle cell crisis was 3.0 (IQR: 1.0-7.0). Details of other characteristics are shown in Table 1.

\section{Chronic complications}

Details of chronic complications found in participants are depicted in Table 2. The mean (SD) age at first stroke was 12.6 (7.3) years. The majority $(52.2 \%)$ of cases of avascular necrosis were on the right hip. The mean age at which participants had their first leg ulcer was $18.6 \pm 7.9$ years. Forty (22.9\%) patients had a systolic murmur. The prevalence of enuresis was similar between children and adults. Eight (4.6\%) participants had opioid tolerance.

\section{Quality of life}

All 111 participants aged 14 years and above were included in the QOL study; their median (IQR) physical component score (PCS) and mental component score (MCS) were 47.3 (43.9-58.5) and 41.0 (38.8-44.6), respectively. The median (IQR) total SF-36 score was 62 (57-66) (Fig. 2). The total score strongly correlated with both the PCS $(r=0.88, p=0.01)$ and the MCS (0.71, $p=0.04$ ) (Fig. 3).

Independent associations of QOL scores are shown in Table 3. Holding everything else constant, on average: every one year increase in age was associated with a decrease in the total QOL score by 0.15 point; urban dwellers had a total score that was about 8 points above that of patients living in rural areas; stroke was associated

Table 1 General characteristics of the study participants

\begin{tabular}{lllc}
\hline Characteristics & & Number & Percent \\
\hline Gender & Females & 93 & 53.1 \\
Age (years) & Males & 82 & 46.9 \\
& $5-15$ & 81 & 46.3 \\
Education & $\geq 16$ & 94 & 53.7 \\
& None & 4 & 2.3 \\
& Primary & 65 & 37.1 \\
Marital status & Secondary & 73 & 41.7 \\
& Tertiary & 33 & 18.9 \\
Residence & Single & 168 & 96.0 \\
& Married & 7 & 4.0 \\
Employment Status & Rural & 9 & 5.1 \\
& Urban & 166 & 94.9 \\
& Unemployed & 155 & 88.6 \\
\hline
\end{tabular}


Table 2 Chronic complications of sickle cell disease

\begin{tabular}{lll}
\hline Complications & Number $(n)$ & Prevalence (\%) \\
\hline Ischemic complications & 47 & 26.9 \\
Refractive eye disorders & 23 & 13.1 \\
Avascular necrosis of the hip & 15 & $18.3^{\text {a }}$ \\
Priapism & 14 & 8.0 \\
Stroke & & \\
Anemic complications & 46 & 26.2 \\
Heart disease & 43 & 24.6 \\
Chronic leg ulcers & 12 & 6.9 \\
Gall stones & & \\
Infectious complications & 34 & 19.4 \\
Osteomyelitis & 24 & 13.7 \\
Septic arthritis & 9 & 5.1 \\
Tuberculosis & & \\
Others & 54 & 30.9 \\
Enuresis & 10 & 5.4 \\
Sleep apnoea & aThe denominator included males only $(n=82)$ &
\end{tabular}

with about a 5-point reduction in the total score while ANH was associated with a 3-point reduction in the total QOL score. Factors associated with poor PCS were ageing, stroke, ANH and chronic leg ulcer. The MCS was higher in urban residents but was lower in females and in patients who had gall stones. Other coefficients were not significantly different from zero.

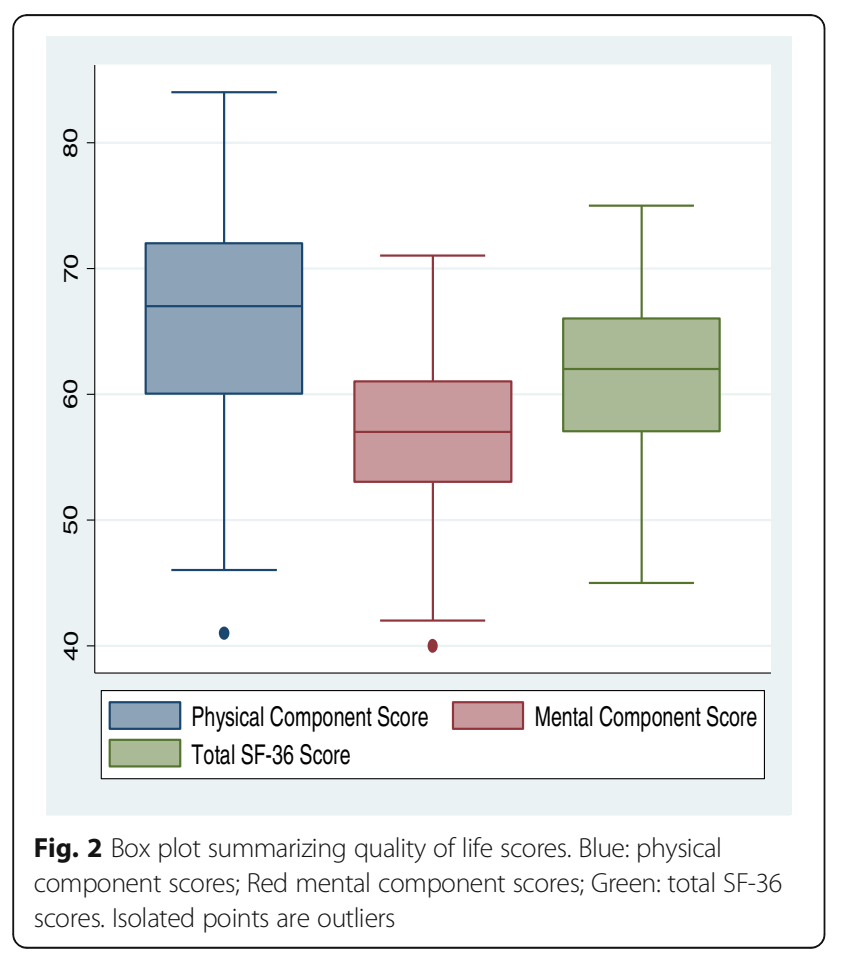

\section{Discussion}

We found in this study that our participants living with SCD are diagnosed late (median of 4 years) contrary to WHO recommendations of new-born screening and diagnosis. With a median age of 16 years, they presented frequent and multiple chronic complications of which $8 \%$ of stroke. The level of care is globally below the standards, and consequently the QOL is poor with the severity associated with age and the presence of chronic complications.

Though late, the diagnosis was however done earlier than was reported by Wonkam et al. in Yaoundé (8.3 years), the capital of Cameroon, in 2014 [11]. Countries that have instituted newborn screening such as Belgium have their diagnosis done earlier (median 0.7 years) have improved the mortality and morbidity of the disease and therefore a better quality of life [12]. Late diagnosis in Cameroon potentially affects the health status and quality of life of the individual, as well as the whole family's economic and psychological wellbeing.

The participants of this study had more frequent painful crises per year than that reported in nearby Nigeria [13] which has adopted systematic follow-up of patients. In addition, only $57 \%$ of our sickle cell population have had some kind of medical follow-up compared to SCD populations in the USA where more than 9 out of 10 do have regular follow up [14].

The prevalence of stroke in this study (8.0\%), was similar to that reported by Njamnshi et al. in 2006 in Yaoundé (6.67\%) [7]. About two fifth of our male study population suffered from priapism (18.3\%), compared to other sickle cell populations in Africa like in Nigeria, where the prevalence was $39.1 \%$ in adults [15]. This probably reflects differences in the age groups studied, as we found that increasing age was significantly associated with priapism. The same reason may explain the lower prevalence of avascular necrosis (AVN) of the hip in our study $(13.1 \%)$ compared with reports from the USA in 2014 (29\%) [16].

The high prevalence of leg ulcers $(24.6 \%)$ is a good indicator of lack of medical follow-up in our study population $[17,18]$. The prevalence of osteomyelitis in this study $(19.4 \%)$ was similar to that obtained from other sickle cell populations [19]. Nocturnal enuresis was the chronic complication with the highest prevalence affecting about one in three persons of our study population (30.1\%). This prevalence was comparable to what has been reported from other studies [20, 21].

All median SF-36 scores in our study were lower than the USA norms studied and implemented in 1998 [10]. This indicates a globally low QOL in our population. The median PCS and MCS we report here (47.3 and 41.0 respectively) suggest that our study population had below normal physical and mental health. 


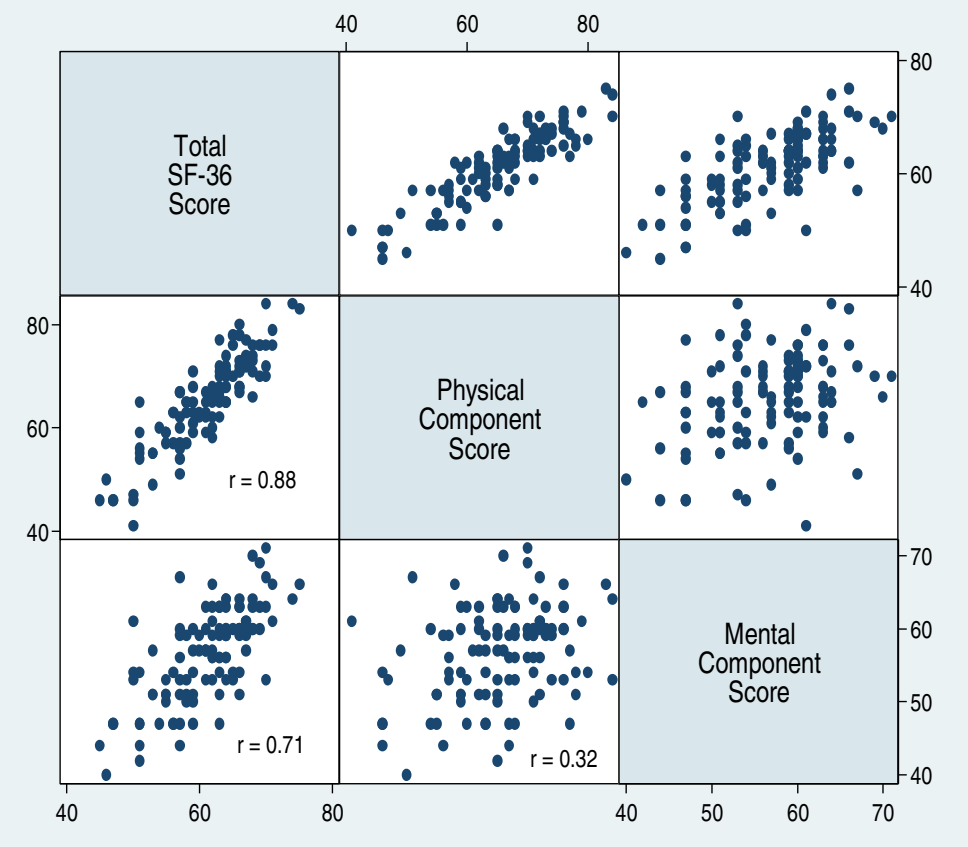

Fig. 3 Correlation matrix between the SF-36 components of quality of life score. The squares with scattered plots represent the areas and directions of correlation of the total scores and the specific scores

Considering the study of Abdel-Monhem Amr et al. conducted in Saudi Arabia in 2011, all the median SF-36 scores in our study were higher than those of their sickle cell population but lower than that of their healthy population [22]. They used a narrower age group (14-18 years) and their questionnaire was administered even during painful episodes.
Our study has potential limitations. Being conducted in the hospital rather than the community, we have probably lost some information like lifestyle factors which can influence patients' outcome. Though all patients had had a confirmed diagnosis of SCD by electrophoresis, we could access only $33 \%$ of results, which did not allow a strong assessment of a potential association

Table 3 Multiple Linear regression models of factors associated with quality of life scores

\begin{tabular}{|c|c|c|c|}
\hline Factor & Regression coefficient (ß) & 95\% confidence interval & $P$-value \\
\hline \multicolumn{4}{|l|}{ Total SF-36 Score, F(4, 105) } \\
\hline Age & -0.15 & -0.28 to -0.02 & 0.025 \\
\hline Urban residence & 7.92 & 2.86 to 13.00 & 0.002 \\
\hline Stroke & -4.85 & -8.76 to -0.94 & 0.015 \\
\hline Avascular necrosis of the hip & -3.35 & -6.11 to -0.60 & 0.018 \\
\hline \multicolumn{4}{|c|}{ Physical Component Score, F(4, 105) } \\
\hline Age & -0.25 & -0.43 to -0.07 & 0.007 \\
\hline Stroke & -8.68 & -14.12 to -3.24 & 0.002 \\
\hline Avascular necrosis of the hip & -4.63 & -8.45 to -0.80 & 0.018 \\
\hline Chronic leg ulcer & -3.70 & -6.75 to -0.65 & 0.018 \\
\hline \multicolumn{4}{|c|}{ Mental Component Score, F(4, 105) } \\
\hline Females & -2.46 & -4.78 to -0.14 & 0.038 \\
\hline Urban residence & 8.29 & 2.76 to 13.80 & 0.004 \\
\hline Gall stones & -4.02 & -7.70 to -0.34 & 0.033 \\
\hline
\end{tabular}


between genotype and QOL. Also, self-reporting of chronic complications may have caused potential report bias. Finally, some files did not have all information required. However, we have provided accurate data on the current standards of care and QOL of individuals living with SCD that may probably guide stakeholders to improve on policies on screening and follow up of these patients in Cameroon.

\section{Conclusions}

The prevalence of chronic complications in sickle cell patients in Cameroon is higher than in most other Sickle cell populations worldwide, probably due to late diagnosis. Chronic complications are also common and are the main drivers of low QOL. Our results highlight the need for national guidelines for SCD control, which should include early or newborn screening programs.

\section{Additional file}

Additional file 1: Questionnaire. (DOCX $21 \mathrm{~kb}$ )

\section{Abbreviations}

ANH: Avascular necrosis of the hip; IQR: Interquartile range; MCS: Mental component score; NBS: New-born screening; PCS: Physical component score; QOL: Quality of life; SCA: Sickle cell anemia; SCD: Sickle cell disease; SD: Standard deviation; SF-36: Short Form-36; WHO: World Health Organization

\section{Acknowledgements}

The authors are grateful to all participants to this study. We also thank members of the 2HD Research Network for their contribution in improving the proposal, and the pediatric team of the Douala Laquintinie Hospital for their contribution. The 2HD Research Network is supported by a Cruddas Link Fellowship to SPC (Tseu Medical Institute, Harris Manchester College, University of Oxford, UK)

\section{Funding}

This work did not receive any funding.

\section{Availability of data and materials}

The datasets generated during and/or analyzed during the current study are not publicly available -because some secondary manuscripts are still being written- but are available from the corresponding author on reasonable request.

\section{Authors' contributions \\ AMA: conception and design of the study, data collection, data interpretation, drafting and review of the manuscript. EDTN: conception and design of the study, data collection, review of the manuscript. CEB: data analysis, data interpretation, drafting and review of the manuscript. VSV: data interpretation, drafting and review of the manuscript. DN: data interpretation, drafting and review of the manuscript. YMD: data interpretation, drafting and review of the manuscript. SPC: conception and design of the study, data collection, data interpretation, drafting and review of the manuscript. All authors revised and approved the final version of the manuscript.}

\section{Authors' information}

Not applicable.

\section{Competing interests}

The authors declare that they have no competing interests.

\section{Ethics approval and consent to participate}

Ethical approval was obtained from the Institutional Review Board of the Faculty of Health Sciences of the University of Buea. Authorizations to conduct the study were obtained from the South-West and Littoral Regional delegations and from the Directors of the three study hospitals. Written informed consent was obtained from all adult participants (above the age of 21 years). Written assent was signed by the guardian of participants aged less than 21 years, after which verbal consent was obtained from the latter.

\section{Publisher's Note}

Springer Nature remains neutral with regard to jurisdictional claims in published maps and institutional affiliations.

\section{Author details}

${ }^{1}$ Department of Internal Medicine and Pediatrics, Faculty of Health Sciences, University of Buea, Buea, Cameroon. ${ }^{2}$ Health and Human Development (2HD) Research Network, P.O. Box 4856, Douala, Cameroon. ${ }^{3}$ Faculty of Medicine and Pharmaceutical Sciences, University of Douala, Douala, Cameroon. ${ }^{4}$ Department of Internal Medicine, Douala General Hospital, P.O. Box 4856, Douala, Cameroon. ${ }^{5}$ Ministry of Public Health, Centre Medical

d'Arrondissement de Bare, Nkongsamba, Cameroon.

Received: 6 October 2016 Accepted: 3 April 2017

Published online: 20 April 2017

\section{References}

1. Ballas SK, Kesen MR, Goldberg MF, Lutty GA, Dampier C, Osunkwo I, et al. Beyond the Definitions of the Phenotypic Complications of Sickle Cell Disease: An Update on Management. Sci World J. 2012;2012:949535.

2. Asnani MR, Reid ME, Ali SB, Lipps G, Williams-Green P. Quality of life in patients with sickle cell disease in Jamaica: rural-urban differences. Rural Remote Health. 2008:8:890.

3. World Health Organization. Sickle-cell disease and other haemoglobin disorders: Fact sheet N³08. 2011. http://www.who.int/mediacentre/ factsheets/fs308/en/. Accessed 4 Sept 2016.

4. Makani J, Cox SE, Soka D, Komba AN, Oruo J, Mwamtemi H, et al. Mortality in Sickle Cell Anemia in Africa: A Prospective Cohort Study in Tanzania. PLoS One. 2011;6:e14699.

5. Akinyanju OO, Otaigbe Al, Ibidapo MOO. Outcome of holistic care in Nigerian patients with sickle cell anaemia. Clin Lab Haematol. 2005;27:195-9.

6. McGann P, Muhongo M, McGann E, Oliveira V de, Santos B, Ware RE. Successful Outcomes Of An Infant Sickle Cell Clinic In Luanda, Angola. Blood 2013:122:2934-2934

7. Njamnshi AK, Mbong EN, Wonkam A, Ongolo-Zogo P, Djientcheu VD, Sunjoh FL, et al. The epidemiology of stroke in sickle cell patients in Yaounde, Cameroon. J Neurol Sci. 2006;250:79-84.

8. Billa RF, Biwole MS, Juimo AG, Bejanga Bl, Blackett K. Gall stone disease in African patients with sickle cell anaemia: a preliminary report from Yaounde, Cameroon. Gut. 1991;32:539-41.

9. Ohene-Frempong K, Weiner SJ, Sleeper LA, Miller ST, Embury S, Moohr JW, et al. Cerebrovascular accidents in sickle cell disease: rates and risk factors. Blood. 1998;91:288-94

10. Ware JE Jr, Sherbourne CD. The MOS 36-item short-form health survey (SF-36). I. Conceptual framework and item selection. Med Care. 1992;30:473-83.

11. Wonkam A, Mba CZ, Mbanya D, Ngogang J, Ramesar R, Angwafo 3rd FF. Psychosocial Stressors of Sickle Cell Disease on Adult Patients in Cameroon. J Genet Couns. 2014;23:948-56.

12. Lê PQ, Dedeken L, Gulbis B, Vermylen C, Vanderfaeillie A, Heijmans C, et al. Low Sickle Cell Disease Mortality In Belgium and Benefit From Hydroxyurea Therapy. Blood. 2013:122:2231.

13. Adegoke SA, Adeodu OO, Adekile AD. Sickle cell disease clinical phenotypes in children from South-Western, Nigeria. Niger J Clin Pract. 2015;18:95-101.

14. Barnes M, French K, Rogers C, Berger W. Outpatient Opioid Use In Adult Patients With Sickle Cell Disease. Blood. 2013;122:4699.

15. Adediran A, Wright K, Akinbami A, Dosunmu A, Oshinaike O, Osikomaiya B, et al. Prevalence of Priapism and Its Awareness amongst Male Homozygous Sickle Cell Patients in Lagos, Nigeria. Adv Urol. 2013:2013:890328.

16. Blinder MA, Russel S, Barnes M. Prevalence of Symptomatic Avascular Necrosis and the Operative Treatment in Adult Patients with Sickle Cell Disease. Blood. 2014;124:1379. 
17. Dampier C, LeBeau P, Rhee S, Lieff S, Kesler K, Ballas S, et al. Health-related quality of life in adults with sickle cell disease (SCD): a report from the comprehensive sickle cell centers clinical trial consortium. Am J Hematol. 2011;86:203-5.

18. Delaney KM, Axelrod KC, Buscetta A, Hassell KL, Adams-Graves PE, Seamon C, et al. Leg ulcers in sickle cell disease: current patterns and practices. Hemoglobin. 2013;37:325-32

19. Menadi A, Chaise F, Bellemere P, Mehalleg M, Atia R. Contribution to the study of bone and joint infections in sickle-cell anemia children: Orthopaedic Proceedings.Bone \& Joint 2008. http://www.bjjprocs. boneandjoint.org.uk/content/90-B/SUPP_II/264.2. Accessed 4 Sept 2016.

20. Ali M, Chakravorty S. Prevalence of nocturnal enuresis and proteinuria in children with sickle cell disease and its relation to severity of painful crises. Arch Dis Child. 2014;99 Suppl 1:A101-2.

21. Lehmann GC, Bell TR, Kirkham FJ, Gavlak JC, Ferguson TF, Strunk RC, et al. Enuresis Associated with Sleep Disordered Breathing in Children with Sickle Cell Anemia. J Urol. 2012;188:1572-6.

22. Abdel-Monhem Amr M, Tawfik AT, Al-Omair AO. Health related quality of life among adolescents with sickle cell disease in Saudi Arabia. Pan Afr Med J. 2011:8:10.

\section{Submit your next manuscript to BioMed Central} and we will help you at every step:

- We accept pre-submission inquiries

- Our selector tool helps you to find the most relevant journal

- We provide round the clock customer support

- Convenient online submission

- Thorough peer review

- Inclusion in PubMed and all major indexing services

- Maximum visibility for your research

Submit your manuscript at www.biomedcentral.com/submit 